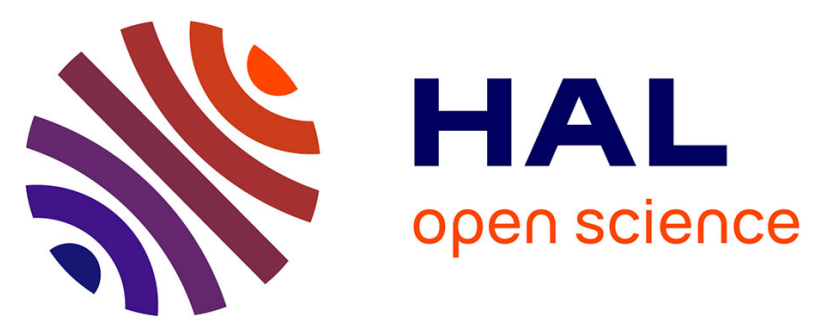

\title{
Preparation of Single-Crystal "House-of-Cards"-like ZSM-5 and Their Performance in Ethanol-to-Hydrocarbon Conversion
}

Zhengxing Qin, Ludovic Pinard, Mohammed Amine Benghalem, T. Jean Daou, Georgian Melinte, Ovidiu Ersen, Shunsuke Asahina, Jean-Pierre Gilson, Valentin Valtchev

\section{To cite this version:}

Zhengxing Qin, Ludovic Pinard, Mohammed Amine Benghalem, T. Jean Daou, Georgian Melinte, et al.. Preparation of Single-Crystal "House-of-Cards"-like ZSM-5 and Their Performance in Ethanol-to-Hydrocarbon Conversion. Chemistry of Materials, 2019, 31 (13), pp.4639-4648. 10.1021/acs.chemmater.8b04970 . hal-03033911

\section{HAL Id: hal-03033911}

\section{https://hal-normandie-univ.archives-ouvertes.fr/hal-03033911}

Submitted on 1 Dec 2020

HAL is a multi-disciplinary open access archive for the deposit and dissemination of scientific research documents, whether they are published or not. The documents may come from teaching and research institutions in France or abroad, or from public or private research centers.
L'archive ouverte pluridisciplinaire HAL, est destinée au dépôt et à la diffusion de documents scientifiques de niveau recherche, publiés ou non, émanant des établissements d'enseignement et de recherche français ou étrangers, des laboratoires publics ou privés. 


\section{Preparation of Single Crystals "House-of-Cards"-}

2 like ZSM-5 and Their Performance in Ethanol-to-

3 Hydrocarbons Conversion

4 Zhengxing Qin, ${ }^{a}$ Ludovic Pinard, ${ }^{b}$ Mohammed Amine Benghalem, ${ }^{b}$ T. Jean Daou, ${ }^{c}$ Georgian

5 Melinte, ${ }^{d}$ Ovidiu Ersen, ${ }^{d}$ Shunsuke Asahina,${ }^{e}$ Jean-Pierre Gilson, ${ }^{f}$ Valentin Valtche ${ }^{f, g^{*}}$

6 a State Key Laboratory of Heavy Oil Processing, College of Chemical Engineering, China

7 University of Petroleum (East China), Qingdao 266580, China

8 ' Institut de Chimie des Milieux et Matériaux de Poitiers (ICM2P), UMR 7285 CNRS, 4 Rue

9 Michel Brunet, Bâtiment B27, 86073 Poitiers Cedex - France.

10 'Université de Haute Alsace (UHA), Université de Strasbourg (UDS), Axe Matériaux à Porosité

11 Contrôlée (MPC), Institut de Science des Matériaux de Mulhouse (IS2M), UMR CNRS 7361,

12 ENSCMu, 3 bis rue Alfred Werner, F-68093 Mulhouse, France

13 Institut de Physique et de Chimie de Strasbourg, Université de Strasbourg 23, rue du Loess BP

14 43, F-67034 Strasbourg, France

15 eSEM Application Team, JEOL Ltd., Akisima, Tokyo 196-8558, Japan

$16{ }^{\mathrm{f}}$ Normandie Univ, ENSICAEN, UNICAEN, CNRS, Laboratoire Catalyse et Spectrochimie, 6

17 Boulevard Maréchal Juin, 14050 Caen, France 
$1{ }^{\mathrm{g}}$ State Key Laboratory of Inorganic Synthesis and Preparative Chemistry, Jilin University,

2 Changchun, 130012, China 


\section{ABSTRACT}

2 The present study reports the unbiased chemical etching of micron-sized ZSM-5 crystals with an

$3 \mathrm{NH}_{4} \mathrm{~F}$ solution resulting in house-of-cards-like single crystals containing large rectangular

4 cavities surrounded by thin $(15-30 \mathrm{~nm})$, flat and highly crystalline walls. The formation of such

5 house-of-cards-like architecture is a result of the preferential extraction of mis-oriented

6 nanocrystalline domains followed by the uniform dissolution of the remaining part of the crystal.

7 The characteristic features of $\mathrm{NH}_{4} \mathrm{~F}$-treated zeolites are the retention of framework composition

8 (Si/Al) and Brønsted acidity, high crystallinity, a moderate increase in external surface area and

9 increased accessibility to their active sites. Such a combination produces zeolitic catalysts with

10 superior performances (activity, stability and coke resistance) in the ethanol-to-hydrocarbons

11 conversion. The physicochemical properties of this newly engineered zeolite are compared with

12 a hierarchical zeolite obtained by caustic leaching and zeolite nano-sheets synthesized with a

13 bifunctional template, a di-quaternary ammonium-type surfactant. 
2 Zeolites revolutionized oil refining and petrochemistry due to their excellent chemical and

3 (hydro)thermal stability, unique microporous structures of molecular dimensions and tunable

4 acidity located in a shape-selective environment [1-3]. With an increasing demand for highly

5 active and stable catalysts for existing and emerging processes, recent work with zeolites focused

6 on morphology tailoring either during their synthesis (bottom-up approach) or by post-synthesis

7 modifications (top-down approach), the so-called zeolite crystal engineering [4-8].

8 Transport limitations in their micropore channels are probably the most serious drawback of

9 zeolite catalysts [9]. Decreasing zeolite crystal size is a straightforward approach to minimize

10 their impact. Advances in the understanding of zeolite nucleation/crystal growth allowed the

11 preparation of nanocrystals of many industrially important zeolites $[10,11]$. However, the

12 number of zeolite crystals synthesized with nanosized dimensions is still limited. Zeolite

13 materials with nano-dimensions in a particular crystallographic direction were also prepared

14 [12]. These two-dimensional microporous materials, referred to as layered- or sheet-like zeolites,

15 offer the advantage of extended external surface areas and enhanced diffusion in a particular

16 crystallographic direction. They were prepared, for instance, by Corma and co-workers by

17 exfoliating layered MWW-type zeolite precursors [13]. The exfoliation approach is however

18 limited to a few zeolites since it works with layered precursors with weaker bonds in a particular

19 crystal direction. Ryoo et al. successfully synthesized a series of crystalline molecular sieves

20 (ZSM-5 and zeolite Beta) with tunable mesostructures and nanosheet or nanosponge

21 morphologies using amphiphilic organosilanes or multi-quaternary ammonium surfactants as

22 bifunctional templates [14-16]. A low-cost approach to zeolite nanosheets forming "house-of-

23 cards" structures was reported by Tsapatsis et al. [17]. They used a template promoting the 
1 repetitive branching of orthogonally connected nanosheets. Such intergrowths generate structures

2 with a mesoporous network of 2-7 $\mathrm{nm}$. The resulting polycrystalline hierarchical materials offer

3 the advantages of higher accessibility for bulky molecules, shorter diffusion pathlengths in the

4 microporosity and a larger external surface area. At present such advanced materials were only

5 obtained by a bottom-up approach. To the best of our knowledge, the preparation of house-of-

6 cards by a top-down approach has not yet been reported. A post-synthesis approach to house-of-

7 cards zeolites would provide significant advantages such as i) applicability to a large number of

8 zeolites; ii) easy transformation of single crystals in house-of-cards materials; iii) cost and

9 environmentally benign scaling-up to produce zeolites.

10 Extraction of framework cations by chemical etching has been used since the first commercial 11 applications of zeolites (eg. hydrocracking, fluid catalytic cracking [FCC], isomerization...) to

12 alleviate these ever-present mass transport limitations. For instance, high-temperature $\left(>600^{\circ} \mathrm{C}\right)$

13 steaming extracts aluminum from zeolite frameworks and redistributes it in extra-framework

14 positions; while the overall $\mathrm{Si} / \mathrm{Al}$ is unchanged, the framework $\mathrm{Si} / \mathrm{Al}$ increases and

15 rearrangement of framework Si generates a secondary mesoporosity [18]. Recently, caustic

16 leaching [19-20] was extensively revisited, better understood and shown to generate secondary

17 mesopores in high silica zeolites [21]. Chemical etching is an efficient and straightforward

18 method to improve intra-crystalline transport and reduce diffusion barriers. However, the

19 preferential or biased extraction of a particular framework cation ( $\mathrm{Al}$ or $\mathrm{Si}$ ) leads to a dissolution

20 profile, strongly dependent on the zeolite composition and therefore difficult to control.

21 Recently, an unbiased chemical etching was developed using $\mathrm{NH}_{4} \mathrm{~F}$ solutions [22-26].

22 Concentrated ammonium fluoride solutions were shown to dissolve Si and $\mathrm{Al}$ from zeolite

23 frameworks at equal rates. While leaving the zeolite composition ( $\mathrm{Si} / \mathrm{Al})$ unchanged, this 
1 approach dissolves preferentially defects in zeolite crystals, such as interfaces between twin

2 crystals, grain boundaries, lattice defects... This unbiased fluoride extraction is HF-free;

3 moreover, the biased $\left(\mathrm{NH}_{4}\right)_{2} \mathrm{SiF}_{6}$ processing of zeolites is currently used in the commercial

4 production of modified (dealumination and subsequent healing by silication) FAU zeolites (LZ-

5210 from UOP LLC. [27-28])

6 The objective of the present work is to develop a universal top-down approach to produce

7 single crystals house-of-cards-like zeolite catalysts. It is based on the recently discovered mosaic

8 structure of zeolite crystals, i.e., the presence of rectangular nanocrystalline domains with well-

9 defined grain boundaries [24]. Such domains were observed in MFI [24], FER [29], FAU [30],

10 and appear to be ubiquitous. They are preferentially dissolved when an unbiased chemical

11 etching is applied to zeolite crystals, leaving behind rectangular cavities several tens of

12 nanometers wide. The remaining part of the crystals dissolves with a similar rate of dissolution

13 following the morphology of extracted nanocrystalline domains, which is employed in the

14 present study to form a house-of-cards-like material by post-synthesis etching. This is illustrated

15 by comparing the unbiased $\mathrm{NH}_{4} \mathrm{~F}$ etching of a parent $\left(\mathrm{Z}_{\mathrm{P}}\right) \mathrm{ZSM}-5$ zeolite, $\mathrm{Z}_{\mathrm{F}}$, a Si biased caustic

16 leaching of the same parent, $\mathrm{Z}_{\mathrm{B}}[31]$, and zeolite nano-sheets $\left(\mathrm{Z}_{\mathrm{NS}}\right)$ prepared with a di-quaternary

17 ammonium-type surfactant acting as a bifunctional structure directing agent [32]. The Ethanol-

18 to-hydrocarbons (ETH) conversion was used as a model reaction to evaluate the catalytic

19 potential of these zeolites and relate it to their physicochemical properties.

\section{2. Results and discussion}

\section{$21 \quad 2.1$ Physicochemical characteristics of the zeolites}


The samples preparation is provided in the supporting information. The XRD patterns of $\mathrm{Z}_{\mathrm{P}}$

2 (commercially available zeolite $\mathrm{ZSM}-5$, the parent), $\mathrm{Z}_{\mathrm{B}}$ (a biased caustic etching of $\mathrm{Z}_{\mathrm{P}}$ ), $\mathrm{Z}_{\mathrm{F}}$ (an

3 unbiased $\mathrm{NH}_{4} \mathrm{~F}$ etched derivative), and $\mathrm{Z}_{\mathrm{NS}}$ (a bottom-up ZSM-5 nanosheets preparation) are

4 displayed in Figure 1. ZP shows sharp and narrow peaks characteristic of a highly crystalline

5 micron-sized MFI-type material. The XRD peaks of $\mathrm{Z}_{\mathrm{F}}$ are equally narrow and well-defined,

6 indicating that the $\mathrm{NH}_{4} \mathrm{~F}$ etching does not impact crystallinity. $\mathrm{Z}_{\mathrm{B}}$ shows much lower peak

7 intensities than its parent. Some of the peaks are missing in the XRD pattern of $Z_{N S}$, as expected

8 for such type of material [32].

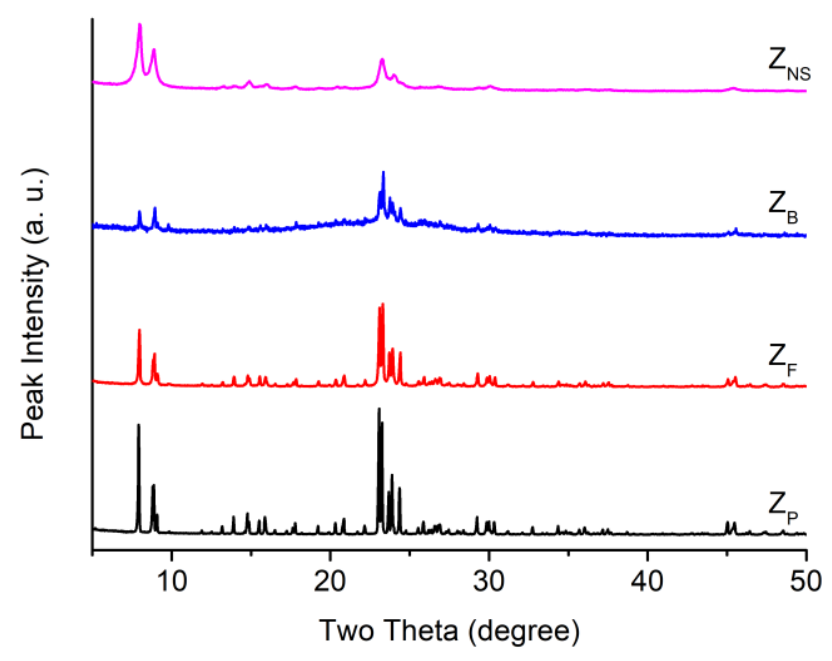

15 Figure 1 The $X R D$ patterns of the parent zeolite $\left(\mathrm{Z}_{\mathrm{P}}\right)$, its $\mathrm{NH}_{4} \mathrm{~F}\left(\mathrm{Z}_{\mathrm{F}}\right)$ and caustic $\left(\mathrm{Z}_{\mathrm{B}}\right)$ etched 16 derivatives, and a nano-sheet zeolite $\left(\mathrm{Z}_{\mathrm{NS}}\right)$.

\section{$17 \quad$ 2.1.2 N$_{2}$ Physisorption}

18 The physicochemical properties of all zeolites are summarized in Table 1. The parent micron-

19 sized $\left(\mathrm{Z}_{\mathrm{P}}\right)$ crystals display a type I isotherm (Figure S1) characteristic of a purely microporous

20 zeolite [33]. $Z_{F}$ and $Z_{B}$ zeolites exhibit a second uptake and a hysteresis loop at high relative 
1 pressure revealing the presence of mesopores. The micropore volume of $Z_{F}$ is fully retained

2 compared to its parent and its external surface area is lower than its caustic leached counterpart,

$3 Z_{B} ; Z_{B}$ has however lost some of its micropore volume, in agreement with the XRD data. The

4 zeolite nano-sheets, $Z_{\mathrm{NS}}$, display a Type I isotherm at low $\mathrm{p} / \mathrm{p}^{0}$ combined with a type IV(a) at

5 high $\mathrm{p} / \mathrm{p}^{0}$. The presence of a hysteresis loop in the relative pressure range $0.4<\mathrm{p} / \mathrm{p}^{0}<1$ is typical

6 for such lamellar materials due to the stacking of nanosheets. $Z_{\text {NS }}$ also exhibits a lower

7 micropore volume and larger external surface area. The mesopores distribution for all samples is

8 presented in Figure 2. No mesopores are observed in the parent micron-sized crystals, $\mathrm{Z}_{\mathrm{P}} . \mathrm{Z}_{\mathrm{F}}$

9 exhibits a large pore size distribution between $c a 10 \mathrm{~nm}$ and more than $100 \mathrm{~nm}$. The $\mathrm{Z}_{\mathrm{B}}$ pore size

10 distribution is also large, but within the mesopore range, i.e., 2 to $50 \mathrm{~nm}$ [33]. The pore size

11 distribution of $Z_{\mathrm{NS}}$, with a maximum of around $6 \mathrm{~nm}$, is much sharper compared with $\mathrm{Z}_{\mathrm{B}}$ and $\mathrm{Z}_{\mathrm{F}}$.

12 All three hierarchical zeolites have a mesopore volume higher than $0.3 \mathrm{~cm}^{3} \mathrm{~g}^{-1}$ (Table 1).

13 However, $Z_{F}$ shows only a slight increase in external surface area compared to its parent.

14 Conversely, $Z_{B}$ and $Z_{N S}$ both develop external surfaces exceeding $200 \mathrm{~m}^{2} \mathrm{~g}^{-1}$. We attribute these

15 differences to the types of pores formed by $\mathrm{NH}_{4} \mathrm{~F}$ and caustic leaching and the stacking of

16 nanosheets, respectively. The dissolution in fluoride medium results in the formation of large

17 meso- and macropores (Figure 2), which exhibit low specific surface area (Table 1). This can be

18 further interpreted based on a rough estimation of the relation between the surface $(S)$, the pore

19 diameter $(d)$ and the pore volume $(V)$ using $d=4 V / S$. In contrast, both $\mathrm{Z}_{\mathrm{B}}$ and $\mathrm{Z}_{\mathrm{NS}}$ contain a

20 substantial amount of small mesopores with size below $10 \mathrm{~nm}$ (Figure 2). Accordingly, a

21 substantial increase in the external surface area is observed (Table 1). 
Table 1. Physicochemical characteristics of the series of ZSM-5 samples.

2

\begin{tabular}{cccccccc}
\hline \multirow{2}{*}{ Samples } & $\mathrm{Si} / \mathrm{Al}^{\mathrm{a}}$ & $\mathrm{S}_{\mathrm{BET}}{ }^{\mathrm{b}}$ & $\mathrm{S}_{\mathrm{ext}}{ }^{\mathrm{c}}$ & $\mathrm{V}_{\text {mic }^{\mathrm{c}}}$ & $\mathrm{V}_{\text {meso }}{ }^{\mathrm{d}}$ & $\mathrm{B}_{\text {Py }}{ }^{\mathrm{e}}$ & $\mathrm{LPy}^{\mathrm{e}}$ \\
\cline { 2 - 8 } & & $\mathrm{m}^{2} \mathrm{~g}^{-1}$ & $\mathrm{~m}^{2} \mathrm{~g}^{-1}$ & $\mathrm{~cm}^{3} \mathrm{~g}^{-1}$ & $\mathrm{~cm}^{3} \mathrm{~g}^{-1}$ & $\mu \mathrm{mol} \mathrm{g}^{-1}$ & $\mu \mathrm{mol} \mathrm{g}^{-1}$ \\
\hline $\mathrm{Z}_{\mathrm{P}}$ & 21 & 377 & 9 & 0.18 & 0.02 & 617 & 91 \\
$\mathrm{Z}_{\mathrm{F}}$ & 22 & 395 & 54 & 0.17 & 0.31 & 582 & 51 \\
$\mathrm{Z}_{\mathrm{B}}$ & 9 & 494 & 206 & 0.13 & 0.36 & 495 & 282 \\
$\mathrm{Z}_{\mathrm{NS}}$ & 37 & 504 & 266 & 0.11 & 0.40 & 162 & 98
\end{tabular}

3 aCP. ${ }^{\mathrm{b} B E T}$ surface area. ${ }^{\mathrm{c}} t$-plot. ${ }^{\mathrm{d}} \mathrm{V}_{\text {meso }}=\mathrm{V}_{\text {total }}-\mathrm{V}_{\text {mic }}\left(\mathrm{V}_{\text {total }}\right.$ : the volume absorbed at $\mathrm{p} / \mathrm{p}^{0}=$

4 0.99). ${ }^{\mathrm{e}}$ The Brønsted $\left(\mathrm{B}_{\mathrm{Py}}\right)$ and Lewis $\left(\mathrm{L}_{\mathrm{Py}}\right)$ acidity were determined by IR analysis of pyridine 5 sorption.

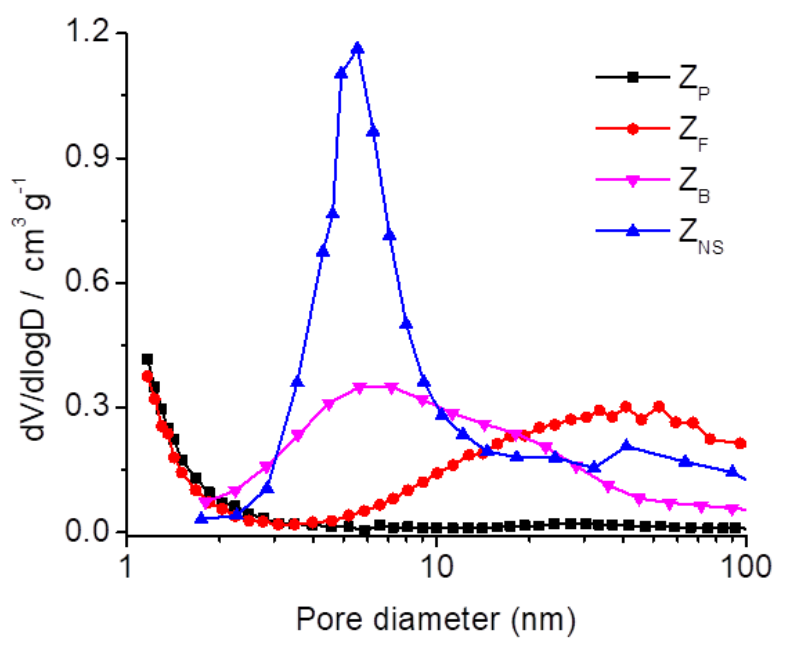

6

7 Figure 2. $\mathrm{BJH}$ pore size distribution of the parent zeolite $\left(\mathrm{Z}_{\mathrm{P}}\right)$, its $\mathrm{NH}_{4} \mathrm{~F}\left(\mathrm{Z}_{\mathrm{F}}\right)$ and caustic $\left(\mathrm{Z}_{\mathrm{B}}\right)$ 8 etched derivatives and the nano-sheet zeolite $\left(\mathrm{Z}_{\mathrm{NS}}\right)$.

\subsubsection{Morphological analysis}


The morphology and secondary porosity of the zeolites are described by combining scanning

2 (SEM) and transmission electron microscopy (TEM). $\mathrm{NH}_{4} \mathrm{~F}$ etching transforms the micron-sized

3 ZSM-5 crystals (Figure 3a, insert) into a foam-like material with thin crystalline walls (Figure

$43 \mathrm{a}, \mathrm{b})$. The macro-morphological features of the crystals are retained. However, the crystalline

5 body is fully transformed into a mosaic of rectangular cavities, large enough to be observed with

6 a scanning electron microscope (Figure $3 \mathrm{a}, \mathrm{b}$ ). TEM provides further insights into the structure

7 and morphology of the $\mathrm{NH}_{4} \mathrm{~F}$ etched zeolite. Figure $3 \mathrm{c}$ shows a representative TEM image of

8 such an $\mathrm{NH}_{4} \mathrm{~F}$ etched ZSM-5 crystal. Figure 3e-g show slices through the electron tomography

9 reconstruction of a selected zeolite grain. The slices highlight the high porosity of chemically

10 treated zeolite but also the remained crystalline pore walls (Figure 3d) with a thickness ranging

11 from 10 to $30 \mathrm{~nm}$. The tomography shows that the $\mathrm{NH}_{4} \mathrm{~F}$ etched zeolite contains two types of

12 secondary pores: i) large interconnected rectangular-shaped, ii) smaller ones probably formed

13 later on during the etching. 3D models indicate that even the vast majority of the smaller

14 mesopores are connected to the secondary porous network, indicating that pore connectivity

15 approaches $100 \%$ and an overall meso-macroporosity of around 47\%. This excellent

16 connectivity between the various pore networks is an important, albeit often overlooked, feature

17 in hierarchical zeolites [34]. The porosity could even be higher as some of the surface pores

18 (Figure S2) were excluded from the quantification. The 3D geometry of the porous network and

19 their walls resemble the "house-of-cards" architecture. A schematic presentation of the

20 remaining part of the crystals with the vast sytem of rectangular, interconnected cavities is

21 presented in Figure $\mathrm{S} 3$. It is remarkable that such a significant secondary porosity increase in $\mathrm{Z}_{\mathrm{F}}$

22 is achieved without loss of intrinsic microporosity and acidity (Table 1) as well as crystallinity

23 (Figure 1, Figure 3d). 

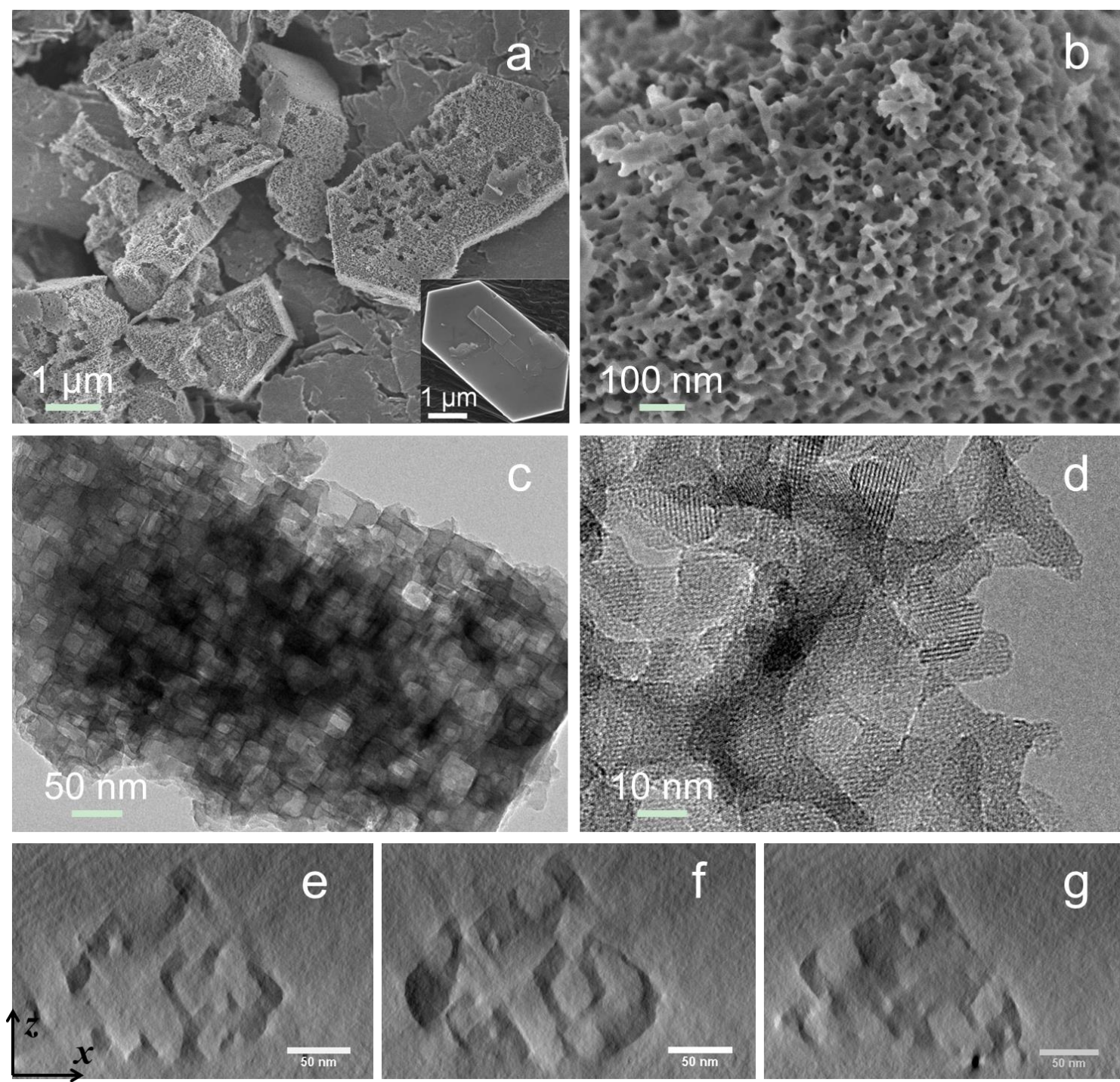

2 Figure 3. Low (a) and high (b) resolution SEM images of $Z_{F}$ sample. Representative low (c) and

3 high (d) resolution TEM images of $\mathrm{Z}_{\mathrm{F}}$. TEM tomography slices in $z x$ direction $(\mathrm{e}, \mathrm{f}, \mathrm{g})$.

5 Zeolite dissolution process is strongly influenced by the zeolite framework composition and

6 crystal zoning in the case of selective chemical extraction of a framework cation [35-37]. The

$7 \quad \mathrm{NH}_{4} \mathrm{~F}$ did not show any sensibility to the framework ratio, including in the case of very low silica 
1 zeolites $[25,26]$. Indeed the $\mathrm{Z}_{\mathrm{F}}$ sample shows a $\mathrm{Si} / \mathrm{Al}$ ratio very similar to its parent (Table $\mathbf{1}$ ).

2 For this reason, we consider that the exceptional resistance of the periferic parts of the crystals to

3 the $\mathrm{NH}_{4} \mathrm{~F}$ etching (Figure 3a, Figure $\mathrm{S} 4$, S5) is an important observation. In order to get a deeper

4 insight into this peculiar "selected-area" dissolution behavior, a comparative study was

5 conducted by combined use of high and low voltage SEM. The electron beam penetrates deep

6 into the sample at high accelerating voltage. Accordingly, the signal will carry information from

7 deeper layers of the sample. In contrast, low voltage high resolution SEM provides only the

8 surface information thanks to the much lower landing voltage [38]. Therefore, as the intensity of

9 the generated secondary electrons varies depending on the magnitude of the accelerating voltage,

10 variations in the roughness of specimen surface and the density of the substance can be detected.

11 As can be seen in Figure S6, the crystal surface of $Z_{P}$ shows a uniform contrast under both high

12 and low voltage observation models. The $5 \mathrm{~min} \mathrm{NH}_{4} \mathrm{~F}$-treated sample also shows a uniform

13 contrast under the low voltage observation model (Figure S7a). In the case of the high voltage

14 model, however, obvious dark areas occur on the $b$ crystal face of the $\mathrm{NH}_{4} \mathrm{~F}$-treated sample

15 (Figure S7b). This contrast difference is not related to crystal surface etching (i.e. surface

16 roughness), since only a few seperated holes can be observed on the $b$ crystal face (Figure S8e).

17 This crystal surface still shows a similar smouth morphology as the untreated sample, with the

18 growth steps clearly distinguishable (Figure S8b, e). In addition, the difference in surface

19 contrast is not an individual but a general phenomenon, as a similar inhomegeneous distribution

20 of the phase contrast was also observed in case of the 10 and 20 min $\mathrm{NH}_{4} \mathrm{~F}$-treated samples

21 (Figure S9). The surface contrast is not so different in the case of the longer time (i.e. 30 and 60

$22 \mathrm{~min}$ ) treated samples (Figure S10). In the later case the original crystal surface are either deeply 
1 etched, or detached as a result of the substantial dissolution of the inner part of zeolite crystals

2 (Figure S11).

3 Based on these intensive SEM observations, we attribute the difference in surface contrast to

4 the difference in density in different parts of zeolite crystals. Namely, the dissolution of zeolite

5 crystals in $\mathrm{NH}_{4} \mathrm{~F}$ solution is spacially inhomogeneous in the macro sense. In general, the inner

6 part of zeolite crystals are preferentially dissolved. The gravimetric measurement of the weight

7 loss of zeolite with the extension of $\mathrm{NH}_{4} \mathrm{~F}$ etching was also conducted (Figure S12). The

8 continuous decrease of the slop of the weight loss curve shows unambiguously that the

9 dissolution of the $Z_{\mathrm{P}}$ crystals is relatively faster at the initial stage and the dissolution rate slows

10 down with increasing etching time (Figure S12). We further attribute the faster dissolution of the

11 inner part to the fast growth rate at the early stage of crystal growth, and the slower dissolution

12 of the crystal periphery to the slow growth rate at the end of the crystallization process where a

13 few defects are formed. Thus the defect-poor parts of the crystals are resistant to the etching.

14 This result is additional evidence showing that the dissolution starts preferentially from

15 framework defects when unbiased etching solution is used.

16 The relation between the crystallographic structure of the zeolite crystals and the etching

17 direction shown in Figure S4 is confirmed by the high-resolution analysis of some similar grains.

18 Figure S13 shows a typical high-resolution TEM image and the corresponding FFT pattern

19 which illustrate that the preferentially etched facets are on $\{010\}$ face, as revealed also by the

20 low-magnification TEM images of the various analyzed zeolite crystals. It should be underlined

21 that the empty cages resulting from the crystal dissolution are orianted along the crystallographic

22 axes. This is a proof for the connection between the growing process and dissolution behaviour 
1 of the crystals. The high-resolution image shown in Figure S14 also sustains this important

2 finding.

3 We attribute both the spacially inhomegeneous dissolution and the facet-dependent etching

4 behavior to the growth mechanism. The fluoride etching is sensitive solely to the zones of

5 structural stress and deffect concentartion (Figure S8d) which are more vulnerable to chemical

6 attack $[24,39,40]$. Thus the dissolution reflects the particularities of the growth process. Layer

7 type growth is characteristic of most of the zeolitic materials [41-44]. The detailed mechanism

8 of MFI growth was revealed recently by in situ AFM microscopy [43]. It was observed that the

9 MFI growth involves two simultaneous phenomenon - oriented attachment of nanoparticle and

10 mono- or low-weight silica species. The nanodomains integrated into the growing crystal contain

11 well defined grain boundaries and thus are rapidly disolved by $\mathrm{NH}_{4} \mathrm{~F}$ etching (Figure $\mathrm{S} 8 \mathrm{c}, \mathrm{f}$ ),

12 leaving behind rectangular cages [24]. These rectangular cages are surrounded by crystalline

13 material, which is a result of the uniform growth by means of low weight silica species. The rate

14 of dissolution of this more stable and uniform part of the crystal is lower (Figure S12). Judging

15 by the straight and flat crystalline walls surrounding the cages the dissolution can be described as

16 "layer-by-layer" process. The results of the present study show that the mechanism of dissolution

17 does not change with the time of treatment and thus a house-of-cards-like material can be

18 synthesized. A fundamental feature of this material is that each "house-of-cards" is a single

19 crystal thanks to the preferential removal of defect-rich zones (Figure 3c). Electron diffraction is

20 a very appropriate technique for the assessment of the crystallinity of various types of specimens

21 at the nanometer level. As shown in Figure S15, the ZSM-5 grains give rise to a unique set of

22 well-defined diffraction spots, allowing us to assign to these crystals a single crystalline

23 structure. In contrast to the interpenetrated "house-of-cards" with myriad intergrown plane 
1 prepared by a bottom-up approach, the single crystal house-of-cards-like material reported here

2 offers highly crystalline with a few frameworks defects left.

3 In order to shed light in the dissolution process and the general applicability of the method, we

4 have employed a series of industrial ZSM-5 sample (see Supporting information). These samples

5 exhibit different morphology and particle size (Figure S16), Si/Al ratio (Table S1) and level of

6 aggregation. The samples were $\mathrm{NH}_{4} \mathrm{~F}$ etched under similar conditions as the time of treatment

7 was varied between 5 and $50 \mathrm{~min}$. The product yield ploted against the etching time is presented

8 in Figure S12. As can be seen, the dissolution rate depends on the crystal size, the larger the

9 crystal size, the lower the dissolurion rate is. We relate this result with the accomplishement of

10 the growth process. As discussed, the well shaped crystals with terminated crystal faces show

11 higher resistnace to the $\mathrm{NH}_{4} \mathrm{~F}$ etching. On the other side, all the trend lines show an initially

12 faster dissolution rate and then converge, with an apparently lower dissolution rate, to a similar

13 product yield value under the applied experimental conditions. This result shows that no matter

14 of basic zeolite crystal characteristics, the mechanism of dissolution is identical and the final

15 product is similar (Figure 3, Figure S17).

16 The silicon selective alkaline etching also leads to a hierarchical zeolite, $Z_{\mathrm{B}}$ (Figure $4 \mathrm{a}, \mathrm{b}$ ). It is

17 a highly porous material with large variation of mesopore size and pore distribution $[31,35]$.

18 Similarly to $\mathrm{NH}_{4} \mathrm{~F}$ etching, the crystal morphology is retained (Figure 4a). However, a closer

19 look reveals a grain-like morphology (Figure 4b), the result of preferential Si extraction and re-

20 deposition of most of the extracted $\mathrm{Al}$ on the etched surface. Such a biased Si etching changes

21 the zeolite framework composition and acidity (Table 1). 
$1 \quad Z_{\text {NS }}$ displays a flower-like morphology composed of interpenetrating plate-like nanosheets

2 (Figure 4c, d). The overall thickness of the lamellar stacking of nanosheets is 20-60 nm (Figure

3 4e). TEM reveals that the stacking "plate" is composed of alternating $2 \mathrm{~nm}$-thick aluminosilicate

4 nanosheets and $2.8 \mathrm{~nm}$ micellar layers (Figure 4f). This well-defined mesoporosity is inherently

5 related to the properties of the structure-directing agent used.
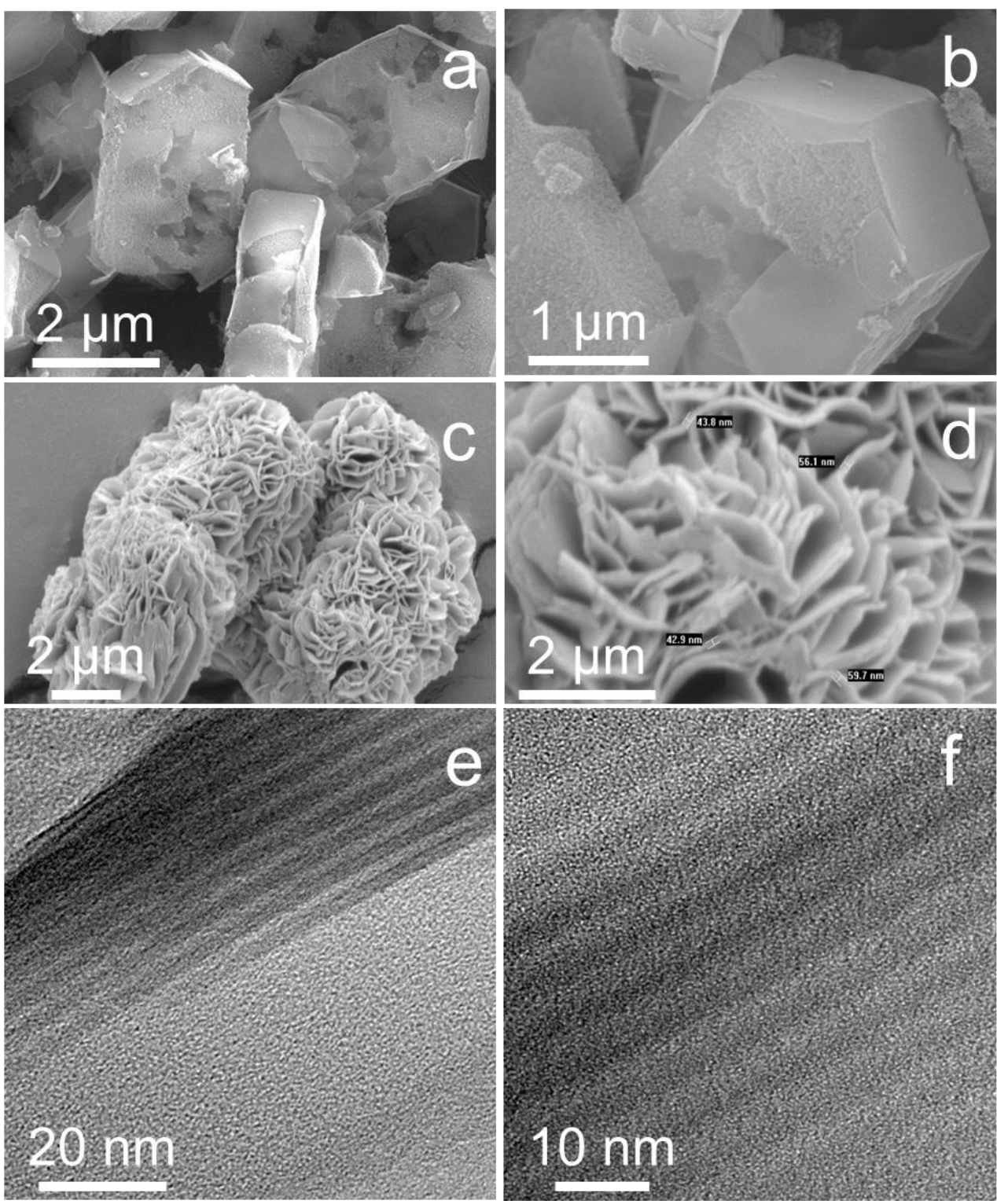
2 Figure 4. Low (a) and high (b) magnification of SEM micrographs of caustic etched ZSM-5

3 crystals, $Z_{\mathrm{B}}$. Low (c) and high (d) magnification images of ZSM-5 nanosheets ( $\mathrm{Z}_{\mathrm{NS}}$ ) prepared by

4 a bottom-up approach. TEM images representing the overall thickness of zeolite lamellas (e) and

5 high-resolution micrograph of ZSM-5 nanosheets building the nanosheet sample (f).

\subsubsection{IR spectroscopy}

7 Chemical analysis of $\mathrm{Z}_{\mathrm{P}}$ and $\mathrm{Z}_{\mathrm{NS}}$ indicates $\mathrm{Si} / \mathrm{Al}$ ratios of 21 and 37, respectively. A negligible

8 change in the $\mathrm{Si} / \mathrm{Al}$ ratio after $\mathrm{NH}_{4} \mathrm{~F}$ etching is observed, while caustic etching produces a

9 material with a Si/Al ratio of 9 (Table 1). These results are expected for unbiased $\left(\mathrm{NH}_{4} \mathrm{~F}\right)$ and

10 biased $(\mathrm{NaOH})$ etchings, respectively [23]. IR spectroscopy of adsorbed pyridine highlights

11 further these conclusions as $Z_{\mathrm{B}}$ has a lower concentration of Brønsted acid sites and a substantial

12 increase of Lewis acid sites compared to its parent $\mathrm{Z}_{\mathrm{P}}$ and its $\mathrm{NH}_{4} \mathrm{~F}$ etched derivative $\mathrm{Z}_{\mathrm{F}}$ (Table

13 1). $Z_{\mathrm{F}}$ Brønsted acidity does not change significantly, as excepted. $Z_{N S}$ has a lower Brønsted acid

14 sites concentration, due to a higher $\mathrm{Si} / \mathrm{Al}$ ratio and the presence of numerous silanols, vide-infra

15 [44]. The pristine surface of all samples can also be probed by FTIR spectroscopy, namely their

$16 v_{(\mathrm{OH})}$ region where isolated silanols $\left(3747 \mathrm{~cm}^{-1}\right)$ located on the external surface and bridged

17 hydroxyls, i.e. Brønsted acid sites $\left(3613 \mathrm{~cm}^{-1}\right)$ are clearly observed (Figure 5). ZP shows such

18 bands and a broad absorption extending from 3500 to $3000 \mathrm{~cm}^{-1}$ (Figure 5a), ascribed to $\mathrm{H}$ -

19 bonded internal silanol nests [45]. The $\mathrm{Z}_{\mathrm{F}}$ spectra does not show such a broad band, and the

20 baseline is almost flat, indicating that a substantial part of the silanols is eliminated during $\mathrm{NH}_{4} \mathrm{~F}$

21 etching. Again, this is the result of a preferential dissolution of highly defective zones in the

22 crystals, a typical characteristic of $\mathrm{NH}_{4} \mathrm{~F}$ etching [24, 40]. In $\mathrm{Z}_{\mathrm{F}}$, the intensity of the $3747 \mathrm{~cm}^{-1}$ 
1 band increases compared to its parent $Z_{\mathrm{P}}$, indicative of an increased external surface area (Table

2 1). For $Z_{\mathrm{B}}$, the intensity of the $3747 \mathrm{~cm}^{-1}$ band further increases while $3613 \mathrm{~cm}^{-1}$ band decreases

3 noticeably. The IR spectra of $Z_{\mathrm{NS}}$ is dominated by external surface silanols at $3743 \mathrm{~cm}^{-1}$ (Figure

$4 \quad 5 a)$ while a very small amount of Brønsted acid sites is detected (Figure 5b).

a

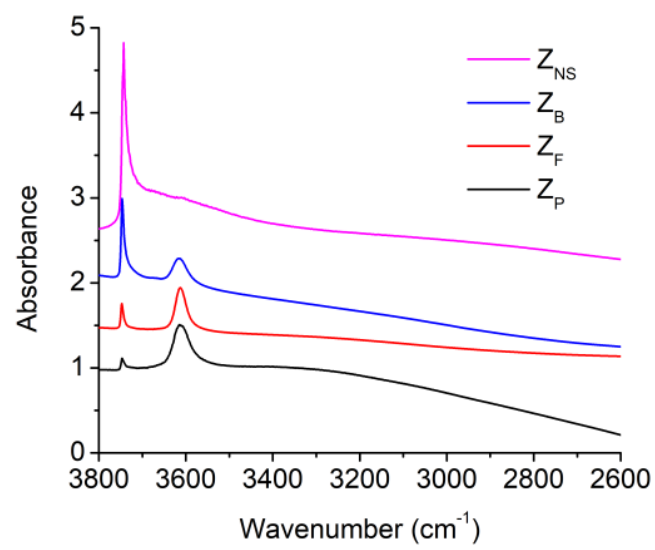

b

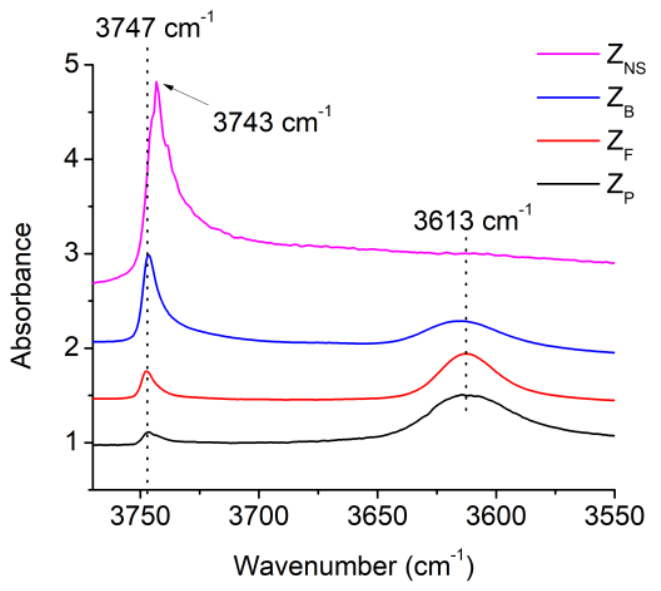

6 Figure 5. IR spectra of $\mathrm{Z}_{\mathrm{P}}, \mathrm{Z}_{\mathrm{F}}, \mathrm{Z}_{\mathrm{B}}$, and $\mathrm{Z}_{\mathrm{NS}}$ in the $2600-3800 \mathrm{~cm}^{-1} v_{(\mathrm{OH})}$ region (a) and zoom on 7 the $v_{(\mathrm{OH})}\left(3550-3770 \mathrm{~cm}^{-1}\right)$ region $(\mathrm{b})$.

8 The above results indicate that a ZSM-5 house-of-cards-like architecture, $\mathrm{Z}_{\mathrm{F}}$, can be prepared

9 by a top-down unbiased $\mathrm{NH}_{4} \mathrm{~F}$ etching of ZSM-5. Single zeolite crystals are converted in a

10 mosaic of connected rectangular cavities separated by nanometer thick crystalline walls. Such

11 walls are thicker than the house-of-cards obtained by a bottom-up approach, $\mathrm{Z}_{\mathrm{NS}}$ (Figure 3e-g

12 and Figure 4e, f). However, the aspect ratios between the wall thickness and mesopore space of

13 both $\mathrm{Z}_{\mathrm{F}}$ and $\mathrm{Z}_{\mathrm{NS}}$ are similar. As mentioned, the formation of rectangular cavities is a

14 consequence of the unbiased dissolution of highly defect zones and small crystalline domains

15 mostly presented in zeolite crystals. Thus, an essential advantage of the top-down approach is 
1 that the "house" is a single crystal almost free of defect zones. A decrease of Lewis acid sites is

2 observed, again a consequence of the preferential dissolution of defective portions of the crystals

3 (Table 1) while the number of Brønsted acid sites is almost unchanged. The resulting house-of-

4 cards-like material comprises relatively large meso- and macro-pores with a flat surface. Another

5 essential feature of the house-of-cards-like material is the moderate increase in external surface

6 area and retention of micropore volume compared to the caustic leached ZSM-5. Nanosheet-like

$7 \quad$ ZSM-5 also shows relatively low micropore volume. $Z_{\mathrm{F}}$ differs substantially from the caustic

8 leached zeolite produced from the same parent $\left(\mathrm{Z}_{\mathrm{B}}\right)$ and the nanosheet $\mathrm{ZSM}-5\left(\mathrm{Z}_{\mathrm{NS}}\right)$. In contrast,

9 the preferential extraction of $\mathrm{Si}$ and redeposition of $\mathrm{Al}$ in the case of $\mathrm{Z}_{\mathrm{B}}$ results in a considerable

10 increase of the external surface area at the expense of the micropore volume, dramatic changes in

11 the chemical composition and the acidic properties of the zeolite (Table 1). Nanosheet ZSM-5

12 also exhibits a huge external surface area and reduced micropore volume. It should be noted the

13 very low Brønsted acidity of this material (Table 1) and the vast presence of surface silanols in

14 this material (Figure 5). This series of catalysts with well distinct physicochemical properties

15 offers the possibility a structure-property relationship to be established.

162.2 Ethanol-to-hydrocarbons (ETH) conversion on $\mathbf{Z}_{\mathrm{B}}, \mathbf{Z}_{\mathrm{F}}$, and $\mathbf{Z}_{\mathrm{NS}}$ zeolite catalysts

17 ETH, like the methanol-to-hydrocarbons (MTH) process, is a key step in the transformation of

18 biomass, coal, natural gas, heavy oils into olefins (major building blocks in petrochemistry) and

19 higher hydrocarbons (gasoline fuel) [46]. The performance of all these four zeolites is evaluated

20 in this reaction as already discussed previously [31]. Ethanol is converted into water and light

21 olefins as well as heavier hydrocarbons (3 to 18 carbon atoms). Small amounts of methane and

22 ethane are detected but no $\mathrm{CO}$ and $\mathrm{CO}_{2}$. The yields are presented as molar \% in the organic

23 fraction (Figures 6 and 7). While ethanol dehydration can take place on weak acid sites, 
1 oligomerization, cyclization and hydrogen transfer reactions require strong acid sites as found in

2 zeolites. On all our catalysts, ethanol conversion is initially complete and decreases slowly with

3 time-on-stream (Figure S18a). Therefore, the catalyst deactivation is related to the time evolution

4 of the $\mathrm{C}_{3+}$ yield.

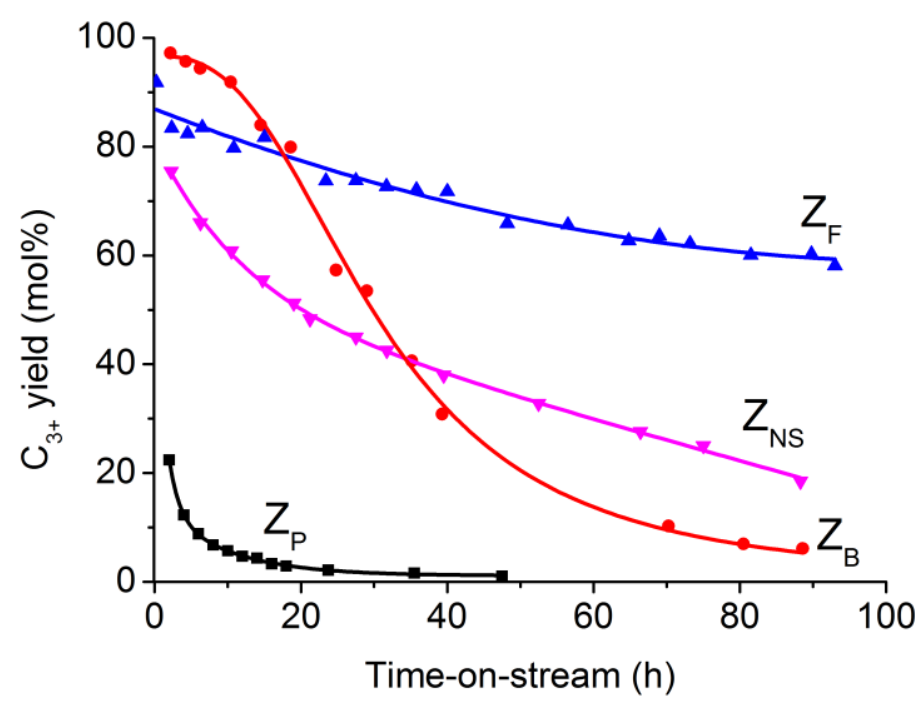

6 Figure 6. Molar yields of $\mathrm{C}_{3+}$ hydrocarbons as a function of time-on-stream during the

7 conversion of ethanol at $623 \mathrm{~K}$ and $3.0 \mathrm{MPa}$ on $\mathrm{Z}_{\mathrm{P}}, \mathrm{Z}_{\mathrm{F}}, \mathrm{Z}_{\mathrm{B}}$, and $\mathrm{Z}_{\mathrm{NS}}$ zeolite catalysts. The lines

8 are drawn simply to guide the eyes.

9 On the parent zeolite $\left(\mathrm{Z}_{\mathrm{p}}\right)$, the initial yield of $\mathrm{C}_{3+}$ is only $35 \%$ (extrapolated value at zero

10 conversion) and decreases rapidly becoming negligible after only $20 \mathrm{~h}$ (Figure 6). On $\mathrm{Z}_{\mathrm{B}}$, the

11 initial $\mathrm{C}_{3+}$ yield is slightly less than $100 \%$ (Figure 6), but the catalyst deactivates rapidly and

12 yields almost no $\mathrm{C}_{3+}$ after $90 \mathrm{~h}$ on stream. On $\mathrm{Z}_{\mathrm{NS}}$, the initial $\mathrm{C}_{3+}$ yield is lower than $\mathrm{Z}_{\mathrm{B}}$ but quite

13 high considering its much lower Brønsted acid site concentration. However, its deactivation rate 
1 is much lower than $Z_{B}$ : after $90 \mathrm{~h}$ on stream, the $C_{3+}$ yield decreases to $c a .20$ mol. $\%$ while it was

2 almost zero on $Z_{\mathrm{B}}$. The direct synthesis of a hierarchical zeolite using a complex surfactant is an

3 efficient, albeit expensive, way of minimizing deactivation. $Z_{F}$, although not the catalyst with the

4 best initial $\mathrm{C}_{3+}$ yield retains it much longer as it deactivates much slower than $\mathrm{Z}_{\mathrm{B}}$ and $\mathrm{Z}_{\mathrm{NS}}$ (Figure

5 6); after $90 \mathrm{~h}$ of TOS, it still produces a substantial $\mathrm{C}_{3+}$ yield, $c a .60 \mathrm{~mol} . \%$.

6 The unbiased $\mathrm{NH}_{4} \mathrm{~F}$ etching of a micrometer-sized ZSM-5 zeolite leads to a diffusion path

7 length similar to that of nanosized one. Indeed, the stability of $\mathrm{Z}_{\mathrm{F}}$ is similar, or even higher for

8 longer reaction time, to that on a commercial zeolite with a crystal size of $45 \mathrm{~nm}$ [31]. See also

9 Figure S19 in the present work. The superior stability of $Z_{F}$ on a nanoscale zeolite can be related

10 to both a high intracrystalline mesoporous volume $\left(0.31 \mathrm{~cm}^{3} \cdot \mathrm{g}^{-1}\right)$ and quasi-perfect connectivity

11 with the microporous network, a consequence of single crystal nature of house-of-cards-like

12 material. $\mathrm{As}_{\mathrm{F}}$ is devoid of defects, contrariwise on $\mathrm{Z}_{\mathrm{NS}}$, the immobilization and growth of coke

13 precursors are mitigated. Therefore the catalyst is more stable. On the other hand, as the caustic

14 leaching divides by only four the diffusion path length as shown by the desorption experiments

15 [47], the gain in stability is rather limited.

16 The molar yields of the paraffins $(\mathrm{P})$, olefins $(\mathrm{O})$, naphthenes $(\mathrm{N})$, and aromatics $(\mathrm{A})$, as well

17 as the paraffins to aromatics molar ratio (P/A), are reported as a function of the $\mathrm{C}_{3+}$ yield and

18 time-on-stream in Figure 7 and Figure S18b-f, respectively. As far as product distribution is

19 concerned $Z_{\mathrm{P}}, Z_{N S}$ and $Z_{\mathrm{P}}$ give the same product selectivity for the same $\mathrm{C}_{3+}$ yield, meaning that

20 the reactions involved are identical, even during the deactivation and regardless of the acid

21 properties of the three catalysts. It is worth to note that a difference exists only on $Z_{B}$ with a yield

22 in $\mathrm{O}_{3+}$. Yields in $\mathrm{N}_{\text {and }} \mathrm{O}_{3+}$ pass through a high yielding maximum in $\mathrm{C}_{3+}$, while those in $\mathrm{P}$ and

23 A increase exponentially. Regardless of $\mathrm{C}_{3+}$ yield the paraffins to aromatics molar ratio (P/A) is 
1 ca. 3 (Figure 7e), indicative of hydrogen transfer between naphthene and olefins (Scheme 1). The

2 initial low value of P/A ratio (open symbol in figure 7e) is due to coke formation.

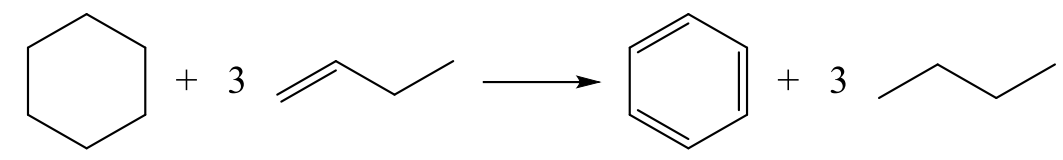

5 Scheme 1. The hydrogen transfer reaction between naphthene and olefins.

6 In sharp contrast, $Z_{\mathrm{F}}$ shows considerably higher aromatic and naphthene yields than $Z_{\mathrm{B}}$ and

$7 \mathrm{Z}_{\mathrm{NS}}$, while its paraffin yield is low (Figure 7a, c, d). Apparently, hydrogen transfer reactions are

8 substantially suppressed in this catalyst. Its P/A is lower than 0.5 (Figure 7e), implying that on

9 the $\mathrm{NH}_{4} \mathrm{~F}$ treated zeolite, aromatics are formed by a monomolecular protolytic dehydrogenation.

10 Lercher and coworkers [48] have shown that a high ratio of Brønsted acid sites to Lewis acid

11 sites (BAS/LAS) minimizes the alkenes concentration and causes high hydride transfer (HT)

12 activity. Yet on $\mathrm{Z}_{\mathrm{F}}$ catalyst, $\mathrm{HT}$ is limited although the house-of-cards-like catalyst possesses the

13 highest BAS/LAS ratio. Lercher et al. [49] also demonstrated that the rate determining step for

14 dehydrogenation activity of alkane on H-ZSM-5 is represented by olefin desorption from the

15 catalyst surface which is promoted by a short diffusion path length. It is worth mentioning that

16 the products selectivity of $Z_{\mathrm{F}}$ is very close to nanometer-sized ZSM-5 zeolite (Figure $S 20$ ),

17 confirming that the diffusion path length is limited to a few nanometers on both zeolites. 

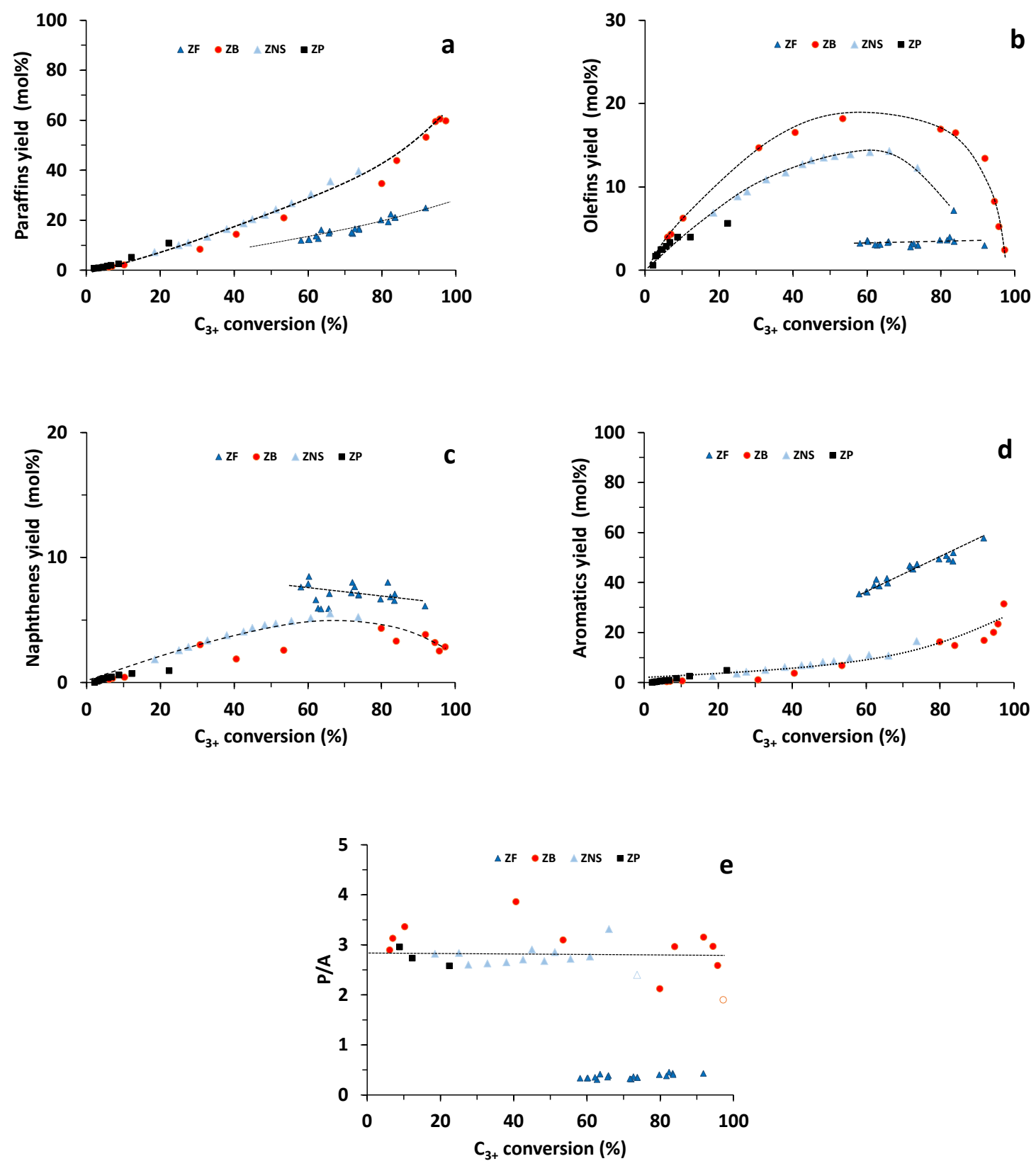

4 Figure 7. Ethanol transformation at $623 \mathrm{~K}$ and 3.0 MPa on $\mathrm{Z}_{\mathrm{P}}, \mathrm{Z}_{\mathrm{F}}, \mathrm{Z}_{\mathrm{B}}$ and $\mathrm{Z}_{\mathrm{NS}}$ zeolite: (a) molar

5 yields of paraffins (P), (b) olefins $\left(\mathrm{O}_{3+}\right),(\mathrm{c})$ naphthenes $(\mathrm{N}),(\mathrm{d})$ aromatics $(\mathrm{A})$, and (e) molar P/A

6 ratio catalysts as a function of $\mathrm{C}_{3+}$ conversion. The lines are drawn simply to guide the eyes.

7 The coke content, the evolution of the number of acid sites (Brønsted and Lewis) and pore

8 volumes accessible to nitrogen after more than $48 \mathrm{~h}$ of reaction are gathered in Table 2 . The coke 
1 content is around $13 \mathrm{wt} \%$ on $\mathrm{Z}_{\mathrm{P}}$ after $48 \mathrm{~h}$ of reaction. $\mathrm{NH}_{4} \mathrm{~F}$ etching has no impact on the coke

2 level, while on the alkaline leached $\mathrm{Z}_{\mathrm{B}}$ catalyst, coke grows continuously to reach a level almost

3 twice as high as its parent. On $\mathrm{Z}_{\mathrm{NS}}$, although its Brønsted acid site concentration is 4 times lower

4 than on $Z_{\mathrm{P}}$, coke content is quite similar. The residual acidity (Brønsted and Lewis), after

5 deactivation, is very low for all samples. An important decrease of micropore volume occurs on

6 all zeolites. On $\mathrm{Z}_{\mathrm{NS}}$ which is the least acidic catalyst, the loss of microporosity is only $25 \%$. The

7 coked $\mathrm{Z}_{\mathrm{F}}$ and $\mathrm{Z}_{\mathrm{NS}}$ catalysts, despite a near total loss of acidity, keep converting ethanol to $\mathrm{C}_{3+}$

8 hydrocarbons ( $20 \%$, and $\sim 20 \%$, respectively, (Figure 6)); ethanol transformation occurring

9 probably by pore mouth catalysis on hybrid active sites (immobilized carbocations) by a carbon

10 pool mechanism [31].

11 Table 2: Coke content, $\mathrm{T}_{50}$ and $\mathrm{T}_{90}$ (temperatures required to remove, by combustion, $50 \%$ and

$1290 \%$ of coke respectively), pore volumes and acidity of $\mathrm{Z}_{\mathrm{P}}, \mathrm{Z}_{\mathrm{F}}, \mathrm{Z}_{\mathrm{B}}$ and $\mathrm{Z}_{\mathrm{NS}}$ zeolite spent

13 catalysts.

\begin{tabular}{ccccccccc}
\hline \multirow{2}{*}{ Samples } & Time & Coke & $\mathrm{T}_{50}$ & $\mathrm{~T}_{90}$ & $\mathrm{~V}_{\text {mic }}{ }^{\mathrm{a}}$ & $\mathrm{V}_{\text {meso }}{ }^{\mathrm{b}}$ & $\mathrm{B}_{\mathrm{Py}}{ }^{\mathrm{c}}$ & $\mathrm{L}_{\mathrm{Py}}{ }^{\mathrm{c}}$ \\
\cline { 2 - 9 } & $\mathrm{h}$ & $\mathrm{wt} \%$ & ${ }^{\circ} \mathrm{C}$ & ${ }^{\circ} \mathrm{C}$ & $\mathrm{cm}^{3} \mathrm{~g}^{-1}$ & $\mathrm{~cm}^{3} \mathrm{~g}^{-1}$ & $\mu \mathrm{mol} . \mathrm{g}^{-1}$ & $\mu \mathrm{mol} \mathrm{g}^{-1}$ \\
\hline $\mathrm{Z}_{\mathrm{P}}$ & 48 & 12.9 & 615 & 705 & 0.01 & 0.02 & 4 & 5 \\
$\mathrm{Z}_{\mathrm{F}}$ & 90 & 12.5 & 560 & 670 & 0.05 & 0.13 & 1 & 10 \\
$\mathrm{Z}_{\mathrm{B}}$ & 110 & 20 & 580 & 680 & 0.03 & 0.36 & 2 & 14 \\
$\mathrm{Z}_{\mathrm{NS}}$ & 90 & 10.5 & 560 & 665 & 0.08 & 0.17 & 0 & 14
\end{tabular}

$14 \mathrm{a} t$-plot. ${ }^{b} \mathrm{~V}_{\text {total }}-\mathrm{V}_{\text {mic }}\left(\mathrm{V}_{\text {total }}\right.$ : the volume absorbed at $\left.\mathrm{p} / \mathrm{p}^{0}=0.99\right) .{ }^{\mathrm{c}}$ The Brønsted acidity $\left(\mathrm{B}_{\mathrm{Py}}\right)$ and 15 Lewis acidity $\left(\mathrm{L}_{\mathrm{Py}}\right)$ determined by pyridine sorption.

16 Differences in the activity and stability between $\mathrm{Z}_{\mathrm{P}}, \mathrm{Z}_{\mathrm{B}}, \mathrm{Z}_{\mathrm{F}}$, and $\mathrm{Z}_{\mathrm{NS}}$ are related to changes in

17 the carbon pool composition. The composition of the coke trapped in the zeolite micropores, i.e., 
1 internal coke, is determined by mineralizing the zeolite and subsequently analyzing the organic

2 phase after a liquid-liquid extraction with $\mathrm{CH}_{2} \mathrm{Cl}_{2}$ [50]. Coke molecules can be lumped in four

3 families according to their number of aromatic rings: alkylbenzenes (I), alkyl naphthalenes (II),

4 alkyl-phenanthrenes or -anthracenes (III) and alkylpyrenes (IV). The sizes of all compounds

5 trapped in the micropores vary between the dimensions of the pore openings $(0.55 \mathrm{~nm})$ and

6 channel intersections $(\sim 1 \mathrm{~nm})$ of $\mathrm{H}-\mathrm{ZSM}-5$. The coke on $\mathrm{Z}_{\mathrm{P}}$ and $\mathrm{Z}_{\mathrm{B}}$ contain representatives of all

7 families. A simpler and lighter coke distribution is found on $\mathrm{Z}_{\mathrm{F}}$ and $\mathrm{Z}_{\mathrm{NS}}$, where families I and III

8 dominate (Figure S21); such a coke composition is similar to that reported elsewhere on nano-

9 sized zeolite [31]. The average molar mass of coke trapped in the micropores, calculated from

10 these compositions, is $200 \mathrm{~g} \mathrm{~mol}^{-1}$ for $\mathrm{Z}_{\mathrm{P}}$ and $\mathrm{Z}_{\mathrm{B}}$, and $180 \mathrm{~g} \mathrm{~mol}^{-1}$ for $\mathrm{Z}_{\mathrm{F}}$ and $\mathrm{Z}_{\mathrm{NS}}$.

11 Taking this average molar mass of $200 \mathrm{~g} \mathrm{~mol}^{-1}$ for the coke molecules trapped inside the

12 micropores ( $c a .13 \mathrm{wt} \%$ on the $\mathrm{Z}_{\mathrm{P}}$ catalysts), its concentration is $c a .645 \mathrm{~mol} \mathrm{~g}^{-1}$, corresponding

13 to the amount of Brønsted acid sites on the fresh zeolite. Coking is therefore mainly a site

14 poisoning effect, further confirmed by a complete disappearance of the bridged $\mathrm{OH}$ groups

15 (Figure S22). Assuming that on all hierarchical zeolites, one coke molecule poisons only one

16 protonic site, the coke trapped within the micropores and that located in the mesopores can be

17 estimated. The results are reported in the bar chart on Figure 8. The most significant

18 accumulations of coke on the mesopores are for the caustic leached micron-sized zeolite $\left(Z_{\mathrm{B}}\right)$ and

19 the nanosheet zeolite $\left(\mathrm{Z}_{\mathrm{NS}}\right)$, reaching up to $55 \%$ and ca. $75 \%$ of the total coke, on the other hand,

20 it is limited to $16 \%$ on the catalyst free of defect $\left(\mathrm{Z}_{\mathrm{F}}\right)$ and as expected, almost zero on the parent

21 zeolite. The accumulation of coke in mesopores is likely related to the quality of the crystals. The

22 increased number of silanols and Lewis acid sites on $Z_{B}$ and $Z_{N S}$ are prone to trap desorbed

23 products [51-53] as confirmed by the disappearance of silanol groups on spent catalysts (Figure 
1 S22). Taking a coke density of $1.1 \mathrm{~g} \mathrm{~cm}^{-3}$, the volume of coke in the micropores corresponds to

2 the loss of micropore volume measured by nitrogen adsorption (Figure 8). These calculated

3 values are very close to the experimental data, highlighting the relevance of this procedure to

4 discriminate between internal and external coke contents.

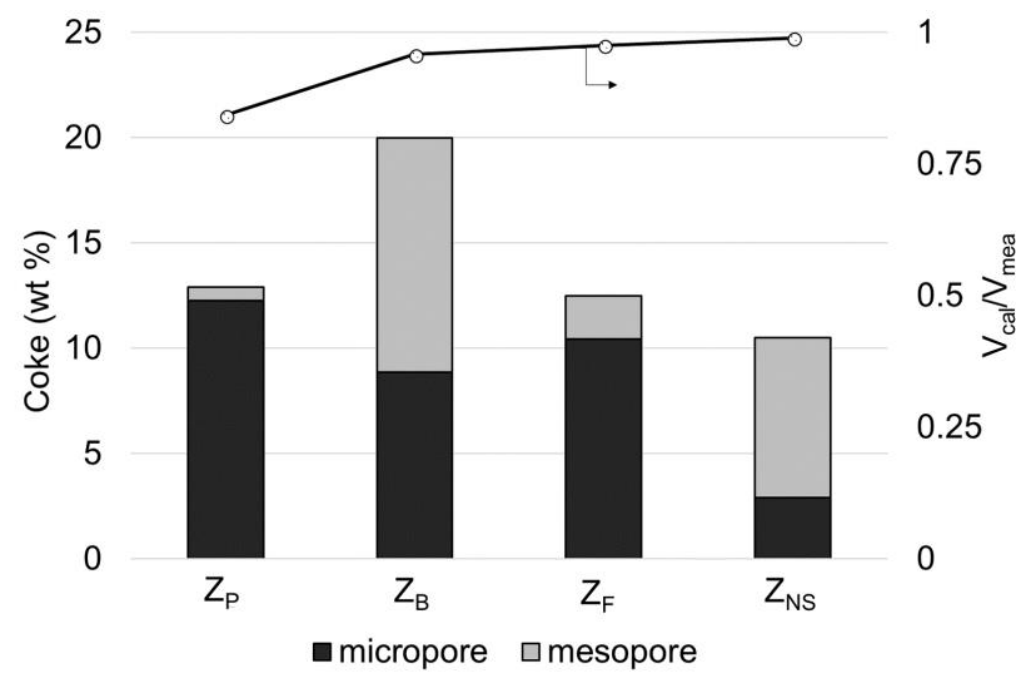

7 Figure 8. Estimation of the coke distribution between micropores and mesopores on $Z_{P}, Z_{F}, Z_{B}$

8 and $Z_{N S}$ zeolite spent catalysts

9 In addition, the coke light-off performances of the spent catalysts are compared in Table 2

10 where temperatures required to combust $50 \%\left(\mathrm{~T}_{50}\right)$ and $90 \%\left(\mathrm{~T}_{90}\right)$ of the coke are reported. $\mathrm{T}_{50}$

11 and $\mathrm{T}_{90}$ are both lower on $\mathrm{Z}_{\mathrm{B}}$ than on $\mathrm{Z}_{\mathrm{P}}\left(-35{ }^{\circ} \mathrm{C}\right.$ and $-25{ }^{\circ} \mathrm{C}$ respectively $)$ and much lower on

$12 \mathrm{Z}_{\mathrm{NS}}$ and $\mathrm{Z}_{\mathrm{F}}\left(-55^{\circ} \mathrm{C}\right)$. The differences are related to a higher accessibility (difusion) of oxygen to

13 the coke molecules trapped in the micropores. The house-of-cards-like zeolite, already the best 
1 catalyst (cumulative performance due to its time stability) is as good as a nanosheet one for

2 regeneration.

3 The ETH reaction illustrates the superior stability and selectivity of $Z_{\mathrm{F}}$, a house-of-cards-like

$4 \quad$ ZSM-5 catalyst, although other hierarchical zeolites, $Z_{\mathrm{B}}$ and $\mathrm{Z}_{\mathrm{NS}}$ possess higher external surface

5 area and mesopore volume. The nano-sheet zeolite $\mathrm{Z}_{\mathrm{NS}}$ with a higher Si/Al ratio of 37 and lower

6 acid site density displays a remarkably high initial $\mathrm{C}_{3}{ }^{+}$yield and was once expected to be a

7 superior candidate for ETH reactions [54] but lacks stability as shown in this study. The $Z_{F}$

8 catalyst outperforms both $Z_{\mathrm{B}}$ and $Z_{\mathrm{NS}}$ in the present study, but the $\mathrm{Z}_{\mathrm{NS}}$ hierarchization procedure

9 brings superior performances than a micron-sized zeolite, $Z_{\mathrm{P}}$ (Figure 6). Zeolite acidity and

10 mesoporosity cannot alone fully explain the differences in catalytic performances discussed

11 above. Based on our detailed comparison of the hierarchical zeolites, we propose that, in addition

12 to mesopore size, shape, uptake capacity and connectivity, the quality of the hierarchical zeolites

13 (micropore accessibility, absence of defects [silanol nests], Lewis acidity) also play important

14 roles in the ETH reaction. The higher catalytic performances of $\mathrm{NH}_{4} \mathrm{~F}$ leached zeolites could also

15 be related to their ability to dehydrogenate naphthenic compounds (Figure 7); this

16 monomolecular reaction requires less space than the bimolecular hydrogen transfer occurring on

17 the caustic leached zeolite and nano-sheet zeolite. The absence of defects combined with a small

18 diffusion pathlength inside the microporosity by retarding the transformation of the desired

19 active carbon pool to unwanted coke, slows catalyst deactivation. The presence of numerous

20 silanol groups, on the other hand, traps coke precursors on the surface, promoting a rapid catalyst

21 deactivation by a fast accumulation of aromatic compounds. Indeed, as coke formation is a

22 genuine shape selective reaction, the availability of more space favors the production of larger

23 molecules, coke, i.e. an inactive carbon pool. These results highlight that, in addition to the 
1 loosely defined "mesopore quality" [21], the surface quality of the remaining microporous

2 crystal domains determines the catalytic performance of hierarchically structured zeolite crystals.

\section{Conclusion}

4 Single house-of-cards-like ZSM-5 crystals were prepared by a top-down approach using a 5 novel unbiased chemical etching with an $\mathrm{NH}_{4} \mathrm{~F}$ solution. Such an etching extracts $\mathrm{Si}$ and $\mathrm{Al}$ at 6 similar rates and preferentially removes less-stable defect zones in the crystals. The process is

7 therefore controlled by the number of intergrowths, the structural stress and the nanocrystalline

8 domains with well-defined grain boundaries, i.e. the history of the zeolite synthesis. Such a

9 unique dissolution behavior is inherently related to the growth process where simultaneous

10 monomer-by-monomer addition and oriented attachment take place [42]. The unbiased $\mathrm{NH}_{4} \mathrm{~F}$

11 dissolution leads to the preferential extraction of misoriented and more vulnerable to chemical

12 attack nanocrystalline domain followed by progressive etching of the remaining part of the

13 crystals, which is more resistant due to the limited number of structural defects. This dissolution

14 proceeds by a layer-by-layer mechanism following the rectangular features of previously

15 extracted nanodomains, thus the well shaped cavities grown in size and connect each other

16 providing a house-of-cards-like morphology.

17 Such a hierarchical material is analogous to a collection of nanosized high quality crystals with

18 the same framework composition and Brønsted acidity of their parent. The high accessibility and

19 short diffusion pathlength offered by the house-of-cards-like morphology is therefore combined

20 with the intact native microporosity and acidity of their parent zeolite and does not require

21 expensive and one-off structure directing agents. The optimization of structural and chemical

22 parameters results in an excellent catalyst easier to regenerate, as demonstrated in the 
1 challenging (deactivation prone) ethanol-to-hydrocarbon reaction. Indeed, regenerating

2 deactivated catalysts by controlled coke combustion often leads to, often overlooked, irreversible

3 changes due to the operating conditions (such an exothermic reaction produces steam near the

4 zeolite active sites and can lead to structural and chemical damages such as dealumination) of

5 this step. The performance of such single crystals house-of-cards-like catalysts is so far second to

6 none as it maintains its performance over longer periods of time and appears easier to regenerate,

7 which even outperforms the nanometer-sized zeolites (Figure S19). Noting that we have

8 previously concluded, based on the samples studied, that the reduction of crystal size is the most

9 efficient way to increase the performance of zeolites for applications such as alcohols to

10 hydrocarbons, and hence nano-zeolites are preferred [31].

11 This study highlights that hierarchical zeolitic catalysts with superior performances can be

12 designed not only by promoting high accessibility and short diffusion to and from their active

13 sites, but also by retaining the crystallinity and acidity of their parents while keeping a minimum

14 level of defects. Since the presence of crystalline domains with well-defined grain boundaries is

15 a ubiquitous in zeolite materials, the preparation of single crystal house-of cards can be extended

16 to other zeolite types. Further insights in the hierarchization process of zeolites, either bottom-up

17 or top-down (this work) hold much potential to design ever bettter zeolite catalysts for current

18 and forthcoming applications [55].

20 Supporting Information. Experimental details, the nitrogen physisorption isotherms, the

21 combined 3D models of zeolite body and pores, the additional SEM and TEM images and a

22 graphical representation of the house-of-cards-like architecture, the additional data of the 
1 Ethanol-to-Hydrocarbons reaction, coke composition by GC analysis, and the IR spectra of the

2 coked zeolite samples.

\section{Corresponding Author}

4 *valentin.valtchev@ensicaen.fr

6 ACKNOWLEDGMENT

7 Zhengxing Qin acknowledges funding support from NSFC 21706285, China University of

8 Petroleum (East China) starting funding, and the Fundamental Research Funds for the Central

9 Universities (18CX02013A). ZQ, JPG and VV acknowledge funding from the French-Sino

10 International Laboratory (LIA) "Zeolites".

12 REFERENCES

13 [1] Martínez C.; Corma A. Inorganic molecular sieves: Preparation, modification and industrial 14 application in catalytic processes. Coordination Chemistry Reviews 2011, 255, 1558-1580.

15 [2] Vermeiren W.; Gilson J.-P. Impact of Zeolites on the Petroleum and Petrochemical Industry. 16 Topics in Catalysis 2009, 52, 1131-1161.

17 [3] Vogt, E. T. C.; Weckhuysen, B. M. Fluid catalytic cracking: recent developments on the 18 grand old lady of zeolite catalysis, Chemical Society Reviews 2015, 44, 7342-7370.

19 [4] Tosheva, L.; Valtchev, V. Nanozeolites: Synthesis, Crystallization Mechanism, and 20 Applications. Chemistry of Materials 2005, 17, 2494-2513.

21 [5] Valtchev, V.; Tosheva, L. Porous Nanosized Particles: Preparation, Properties, and 22 Applications. Chemical Reviews 2013, 113, 6734-6760. 
1 [6] Fan, W.; Snyder, M.; Kumar, S.; Lee, P.; Yoo, W.; McCormick, A.; Penn, R.; Stein, A.;

2 Tsapatsis, M. Hierarchical nanofabrication of microporous crystals with ordered 3 mesoporosity. Nature Materials 2008, 7, 984-991.

4 [7] Awala, H.; Gilson, J.-P.; Retoux, R.; Boullay, P.; Goupil, J.-M.; Valtchev, V.; Mintova, S. 5 Template-free nanosized faujasite-type zeolites. Nature Materials 2015, 14, 447-451.

6 [8] Valtchev, V.; Majano, G.; Mintova, S.; Perez-Ramirez, J. Tailored crystalline microporous 7 materials by post-synthesis modification. Chemical Society Reviews 2013, 42, 263-290.

8 [9] Hartmann, M.; Machoke, A. G.; Schwieger, W. Catalytic test reactions for the evaluation of $9 \quad$ hierarchical zeolites. Chemical Society Reviews 2016, 45, 3313-3330.

10 [10] Smaihi, M.; Barida, O.; Valtchev, V. Investigation of the Crystallization Stages of LTA-Type 11 Zeolite by Complementary Characterization Techniques. European Journal of Inorganic $12 \quad$ Chemistry 2003, 24, 4370-4377.

13 [11] Valtchev, V. Preparation of regular macroporous structures built of intergrown silicalite-1 14 nanocrystals. Journal of Materials Chemistry 2002, 12, 1914-1918.

15 [12] Tsapatsis, M. 2-dimensional zeolites. AIChE Journal. 2014, 60, 2374-2381.

16 [13]Corma, A.; Fornes, V.; Pergher, S. B.; Maesen, T. L. M.; Buglass, J. G. Delaminated zeolite 17 precursors as selective acidic catalysts. Nature 1998, 396, 353-356.

18 [14]Choi, M.; Cho, H. S.; Srivastava, R.; Venkatesan, C.; Choi, D.-H.; Ryoo, R. Amphiphilic 19 organosilane-directed synthesis of crystalline zeolite with tunable mesoporosity. Nature $20 \quad$ Materials 2006, 5, 718-723.

21 [15]Choi, M.; Na, K.; Kim, J.; Sakamoto, Y.; Terasaki, O.; Ryoo, R. Stable single-unit-cell 22 nanosheets of zeolite MFI as active and long-lived catalysts. Nature 2009, 461, 246-249.

23 [16]Na, K.; Jo, C.; Kim, J.; Cho, K.; Jung, J.; Seo, Y.; Messinger, R. J.; Chmelka, B. F.; Ryoo, R. 
Directing Zeolite Structures into Hierarchically Nanoporous Architectures. Science 2011, 333, 328-332.

[17]Zhang, X.; Liu, D.; Xu, D.; Asahina, S.; Cychosz, K. A.; Agrawal, K. V.; Al Wahedi, Y.; Bhan, A.; Al Hashimi, S.; Terasaki, O.; Thommes, M.; Tsapatsis, M. Synthesis of SelfPillared Zeolite Nanosheets by Repetitive Branching, Science 2012, 336, 1684-1687.

[18] van Donk, S.; Janssen, A. H.; Bitter, J. H.; de Jong, K. P. Generation, Characterization, and Impact of Mesopores in Zeolite Catalysts. Catalysis Reviews-Science and Engineering 2003, 45, 297-319.

[19] Young D. A. Hydrocarbon conversion process and catalyst comprising a crystalline aluminosilicate leached with sodium hydroxide. US Pat. 3,326,797, assigned to Unocal, 1964.

[20] Gilson, J.-P.; Nanne, J. M.; Den Otter, G. J. Process for isomerizing hydrocarbons. EP 0398416, assigned to Shell, 1989.

[21]Milina, M.; Mitchell, S.; Crivelli, P.; Cooke, D.; Pérez-Ramírez, J. Mesopore quality determines the lifetime of hierarchically structured zeolite catalysts. Nature Communications $2014,5,3922$.

[22] Valtchev, V.; Balanzat, E.; Mavrodinova, V.; Diaz, I.; El Fallah, J.; Goupil, J.-M. High Energy Ion Irradiation-Induced Ordered Macropores in Zeolite Crystals. Journal of the American Chemical Society 2011, 133, 18950-18956.

[23]Qin, Z.; Gilson, J.-P.; Valtchev, V. Mesoporous zeolites by fluoride etching. Current Opinion in Chemical Engineering 2015, 8, 1-6.

[24]Qin, Z.; Melinte, G.; Gilson, J.-P.; Jaber, M.; Bozhilov, K.; Boullay, P.; Mintova, S.; Ersen, O.; Valtchev, V. The Mosaic Structure of Zeolite Crystals. Angewandte Chemie International Edition 2016, 55, 15049-15052. 
1 [25]Qin, Z.; Cychosz, K. A.; Melinte, G.; El Siblani, H.; Gilson, J.-P.; Thommes, M.; Fernandez,

2 C.; Mintova, S.; Ersen, O.; Valtchev, V. Opening the Cages of Faujasite-Type Zeolite.

3 Journal of the American Chemical Society 2017, 139, 17273-17276.

4 [26] Valtchev, V.; Gilson, J.-P.; Qin, Z. Method for the preparation of synthetic crystalline zeolite 5 materials with enhanced total pore volume. WO 2016005783 A1, assigned to CNRS, 2016.

6 [27]Breck, D. W.; Skeels, G. W. Silicon substituted zeolite compositions and process for 7 preparing same. U.S. Patent 4,503,023, assigned to Union Carbide. 1985.

8 [28] Skeels, G. W.; Breck, D. W. in Proceedings of the Sixth International Zeolite

$9 \quad$ Conference, Olson, D.; Bisio, A. Eds.; Butterworths, Guildford, UK, 1984; p. 87.

10 [29]Chen, X.; Todorova, T.; Vimont, A.; Ruaux, V.; Qin, Z.; Gilson, J.-P.; Valtchev, V. In situ and 11 post-synthesis control of physicochemical properties of FER-type crystals. Microporous and 12 Mesoporous Materials 2014, 200, 334-342.

13 [30] Ajot, H.; Joly, J. F.; Lynch, J.; Raatz, F.; Caullet, P. Formation of Secondary Pores in Zeolites

14 During Dealumination: Influence of The Crystallographic Structure and Of the Si/Al Ratio.

15 In Studies in Surface Science and Catalysis, Rodriguez-Reinoso, F., Rouquerol, J., Sing, K.

16 S. W., Unger, K. K., Eds.; Elsevier: 1991; Vol. 62, p 583-590.

17 [31]Lakiss, L.; Ngoye, F.; Canaff, C.; Laforge, S.; Pouilloux, Y.; Qin, Z.; Tarighi, M.; Thomas, 18 K.; Valtchev, V.; Vicente, A.; Pinard, L.; Gilson, J.-P.; Fernandez, C. On the remarkable 19 resistance to coke formation of nanometer-sized and hierarchical MFI zeolites during 20 ethanol to hydrocarbons transformation. Journal of Catalysis 2015, 328, 165-172.

21 [32]Boltz, M.; Losch, P.; Louis, B.; Rioland, G.; Tzanis, L.; Daou, T. J. MFI-type zeolite 22 nanosheets for gas-phase aromatics chlorination: a strategy to overcome mass transfer 23 limitations. RSC Advances 2014, 4, 27242-27249. 
[33]Thommes, M.; Kaneko, K.; Neimark Alexander, V.; Olivier James, P.; Rodriguez-Reinoso, F.; Rouquerol, J.; Sing K. S.W. Physisorption of gases, with special reference to the evaluation of surface area and pore size distribution (IUPAC Technical Report). Pure and Applied Chemistry 2015, 87, 1051-1069.

[34] Kortunov, P.; Vasenkov, S.; Kärger.; J. Valiullin, R.; Gottschalk, P.; Fé Elía, M.; Perez, M.; Stöcker, M.; Drescher, B.; McElhiney, G.; Berger, C.; Gläser, R.; Weitkamp, J. The role of mesopores in intracrystalline transport in USY zeolite: PFG NMR diffusion study on various length scales. Journal of the American Chemical Society, 2005, 127, 13055-13059.

[35]Groen, J. C.; Bach, T.; Ziese, U.; Paulaime-van Donk, A. M.; de Jong, K. P.; Moulijn, J. A.; Pérez-Ramírez, J. Creation of Hollow Zeolite Architectures by Controlled Desilication of AlZoned ZSM-5 Crystals. Journal of the American Chemical Society, 2005, 127, 10792-10793.

[36]Mei, C.; Liu, Z.; Wen, P.; Xie, Z.; Hua, W.; Gao, Z. Regular HZSM-5 microboxes prepared via a mild alkaline treatment. Journal of Materials Chemistry, 2008, 18, 3496-3500.

[37]Danilina, N.; Krumeich, F.; Castelanelli, S. A.; van Bokhoven, J. A. Where Are the Active Sites in Zeolites? Origin of Aluminum Zoning in ZSM-5. The Journal of Physical Chemistry C, 2010, 114, 6640-6645.

[38] Suga, M.; Asahina, S.; Sakuda, Y.; Kazumori, H.; Nishiyama, H.; Nokuo, T.; Alfredsson, V.; Kjellman, T.; Stevens, S. M.; Cho, H. S.; Cho, M.; Han, L.; Che, S.; Anderson, M. W.; Schüth, F.; Deng, H.; Yaghi, O. M.; Liu, Z.; Jeong, H. Y.; Stein, A.; Sakamoto, K.; Ryoo, R.; Terasaki, O. Recent progress in scanning electron microscopy for the characterization of fine structural details of nano materials. Progress in Solid State Chemistry, 2014, 42, 1-21.

[39] Wang, Y.; Lin, M.; Tuel, A. Hollow TS-1 crystals formed via a dissolution-recrystallization process. Microporous and Mesoporous Materials, 2007, 102, 80-85. 
1 [40]Qin, Z.; Lakiss, L.; Gilson, J. P.; Thomas, K.; Goupil, J. M.; Fernandez, C.; Valtchev, V.

2 Chemical Equilibrium Controlled Etching of MFI-Type Zeolite and Its Influence on Zeolite

3 Structure, Acidity, and Catalytic Activity. Chemistry of Materials 2013, 25, 2759-2766.

4 [41] Anderson, M. W.; Agger, J. R.; Hanif, N.; Terasaki, O. Growth models in microporous 5 materials. Microporous and Mesoporous Materials, 2001, 48, 1-9.

6 [42]Meza, L. I.; Anderson, M. W.; Agger, J. R.; Cundy, C. S.; Chong, C. B.; Plaisted, R. J.

7 Controlling Relative Fundamental Crystal Growth Rates in Silicalite: AFM Observation.

8 Journal of the American Chemical Society, 2007, 129, 15192-15201.

9 [43]Lupulescu, A. I.; Rimer, J. D. In Situ Imaging of Silicalite-1 Surface Growth Reveals the 10 Mechanism of Crystallization. Science, 2014, 344, 729-732.

11 [44]De Yoreo, J. J.; Gilbert, P. U. P. A.; Sommerdijk, N. A. J. M.; Penn, R. L.; Whitelam, S.; 12 Joester, D.; Zhang, H.; Rimer, J. D.; Navrotsky, A.; Banfield, J. F.; Wallace, A. F.; Michel, F. 13 M.; Meldrum, F. C.; Cölfen, H.; Dove, P. M. Crystallization by particle attachment in 14 synthetic, biogenic, and geologic environments. Science, 2015, 349, aaa6760.

15 [45]Lønstad Bleken, B.-T.; Mino, L.; Giordanino, F.; Beato, P.; Svelle, S.; Lillerud, K. P.; 16 Bordiga, S. Probing the surface of nanosheet H-ZSM-5 with FTIR spectroscopy. Physical 17 Chemistry Chemical Physics 2013, 15, 13363-13370.

18 [46]Derouane, E. G.; Nagy, J. B.; Dejaifve, P.; van Hooff, J. H. C.; Spekman, B. P.; Védrine, J. C.; 19 Naccache, C. Elucidation of the mechanism of conversion of methanol and ethanol to 20 hydrocarbons on a new type of synthetic zeolite. Journal of Catalysis, 1978, 53, 40-55.

21 [47]Meunier, F. C.; Verboekend, D.; Gilson, J.-P.; Groen, J. C.; Pérez-Ramírez, J. Influence of 22 crystal size and probe molecule on diffusion in hierarchical ZSM-5 zeolites prepared by 23 desilication. Microporous and Mesoporous Materials, 2012, 148, 115-121. 
1 [48]Feller, A.; Guzman, A.; Zuazo, I.; Lercher, J. A. On the mechanism of catalyzed 2 isobutane/butene alkylation by zeolites. Journal of Catalysis, 2004, 224, 80-93.

3 [49] Narbeshuber, T. F.; Brait, A.; Seshan, K.; Lercher, J. A. Dehydrogenation of Light Alkanes 4 over Zeolites. Journal of Catalysis, 1997, 172, 127-137.

5 [50] Magnoux, P.; Roger, P.; Canaff, C.; Fouche, V.; Gnep, N. S.; Guisnet, M. New Technique for 6 the Characterization of Carbonaceous Compounds Responsible for Zeolite Deactivation. In $7 \quad$ Studies in Surface Science and Catalysis, Delmon, B., Froment, G. F., Eds.; Elsevier: 1987; $8 \quad$ Vol. 34, p 317-330.

9 [51]Barbera, K.; Bonino, F.; Bordiga, S.; Janssens, T. V. W.; Beato, P. Structure-deactivation 10 relationship for ZSM-5 catalysts governed by framework defects. Journal of Catalysis 2011, $11280,196-205$.

12 [52]Thibault-Starzyk, F.; Vimont, A.; Gilson, J.-P. 2D-COS IR study of coking in xylene 13 isomerisation on H-MFI zeolite. Catalysis Today 2001, 70, 227-241.

14 [53]Lee, K.; Lee, S.; Jun, Y.; Choi, M. Cooperative effects of zeolite mesoporosity and defect 15 sites on the amount and location of coke formation and its consequence in deactivation. 16 Journal of Catalysis 2017, 347, 222-230.

17 [54] Madeira, F. F.; Tayeb, K. B.; Pinard, L.; Vezin, H.; Maury, S.; Cadran, N. Ethanol 18 transformation into hydrocarbons on ZSM-5 zeolites: Influence of Si/Al ratio on catalytic 19 performances and deactivation rate. Study of the radical species role. Applied Catalysis A: 20 General 2012, 443-444, 171-180.

21 [55]Ennaert, T.; Van Aelst, J.; Dijkmans, Jan.; De Clercq, R.; Schutyser, W.; Dusselier, M.; 22 Verboekend, D.; Sels, B. F. Potential and Challenges of Zeolite Chemistry in the Catalytic 23 Conversion of Biomass. Chemical Society Reviews 2016, 45, 584-611. 


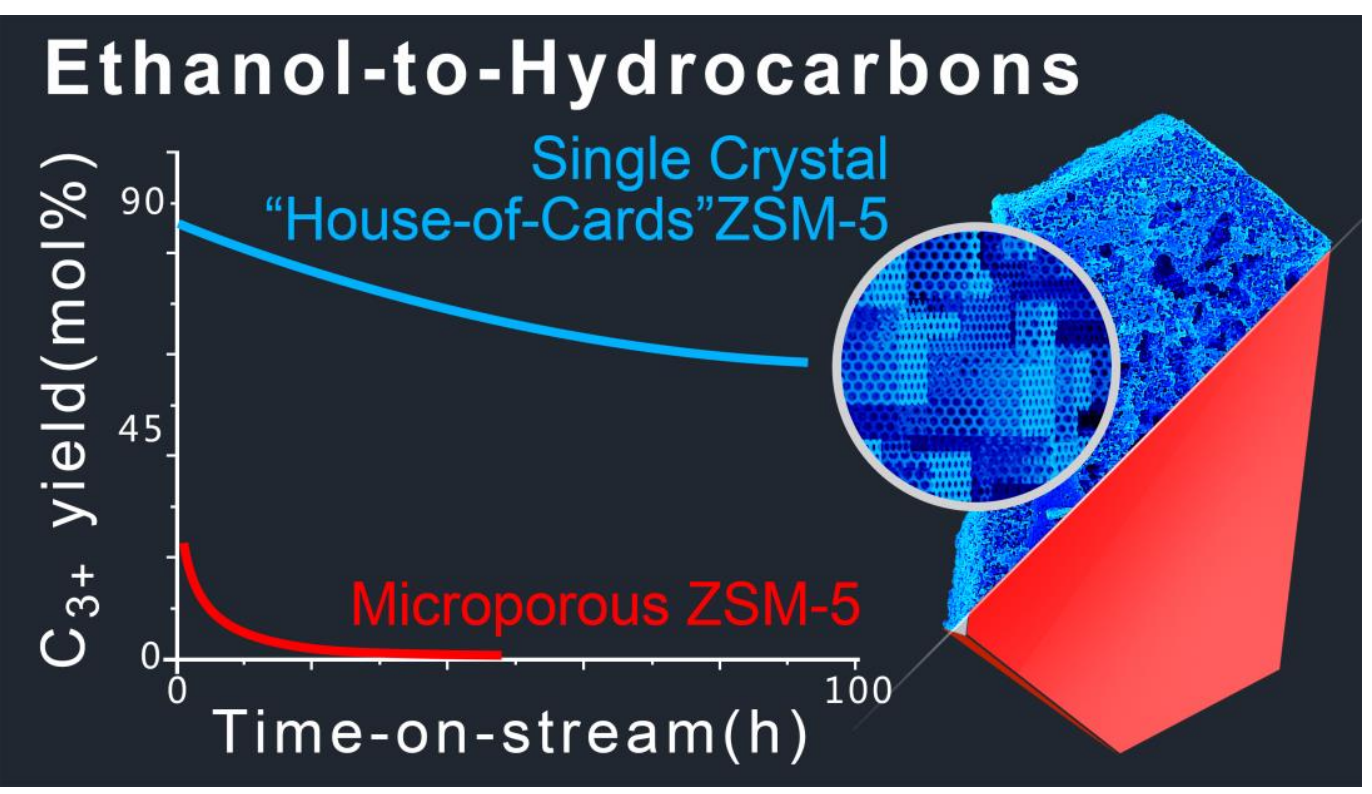

